\title{
Morphological Characteristics and Somatic Incompatibility of Ganoderma from Infected Oil Palm from Three Inland Estates
}

\author{
Latiffah, Z.* and Ho, Y.W. \\ Institute of Bioscience, Universiti Putra Malaysia, 43400 Serdang, Selangor \\ Email: Lfah@usm.my
}

\begin{abstract}
The morphological characteristics of Ganoderma basidiomata from infected oil palms from three inland estates showed some variations, but all fall within the description of $G$. boninense, based on Steyaert's classification system (1967, 1975). Pairings of $G$. boninense isolates from the same estate showed that there was somatic incompatibility among the isolates which indicated that the isolates were distinct individuals and not clones of single genotypes.
\end{abstract}

Keywords: Ganoderma, oil palm, somatic incompatibility

\section{INTRODUCTION}

Basal stem rot caused by Ganoderma is the most serious disease of oil palm in Malaysia. The disease was first reported by Thompson (1931) and was initially considered a disease of older palms. However, with successive planting of oil palm in the same field and planting in areas that previously supported coconut, the disease began to appear in much younger palms of 10 to 15 years old (Turner, 1981). Now, Ganoderma has been found to infect oil palms of 1 to 2 years old, particularly in replanted areas (Singh, 1990).

The highest disease incidence is in coastal areas (Navaratnam, 1964; Turner, 1981; Khairudin, 1990). This is attributed to planting in previous coconut stands (Turner, 1981) and the nature of the soil and its water table (Turner, 1981; Singh, 1990; Khaurudin, 1990). In the past ten years, the disease has also been detected in inland areas (Singh, 1990; Khairudin, 1990; Benjamin and Chee, 1995). The disease usually occurs in the valleys and occasionally on the hill slopes (Singh, 1991). Disease incidence between $2 \%$ to $5 \%$ had been reported in two inland areas i.e. Gomali Estate, Johor, and Regent Estate, Malacca (Khairudin, 1990). Other disease incidences in inland areas were in Batu Anam, North Johor, where 29\% to $50 \%$ of 27 -year-old oil palms planted in Munchong soil series were affected by the disease and in Gemencheh, Negeri Sembilan, where $11.7 \%$ of 27 -year-old oil palms planted on lateritic soil were also infected by the disease (Benjamin and Chee, 1995). Pathogenicity test of $G$. boninense on oil palm seedlings grown on inland and coastal soil types showed mortality rate of $60 \%$ to $70 \%$ which indicated that oil palm seedlings grown on inland soils are as easily infected by the disease as those grown on coastal soils (Ho and Khairudin, 1995).

\section{*Corresponding author}

Present address: School of Biological Sciences, Universiti Sains Malaysia, 11800 Minden, Penang.
A number of studies have been carried out on species identification of Ganoderma in the coastal areas but there is very limited information on Ganoderma from the inland areas. Thus, the present investigation was conducted to study the morphological characteristics of Ganoderma from three inland estates and to determine the somatic incompatibility of the Ganoderma isolates from the same estate to establish whether they were different genotypes or clones of single genotypes.

\section{MATERIALS AND METHODS}

\section{Morphological Studies}

A total of 182 Ganoderma basidiomata were collected from living infected oil palms from three inland estates, namely, Bukit Serampang Estate, Tangkak, Johor; Regent Estate, Tampin, Negeri Sembilan and Paya Lang, Segamat, Johor. Most of the infected oil palms showed obvious skirting symptom. Collection of basidiomata was made from the same tree as well as adjacent trees.

The morphological characteristics used to study the Ganoderma basidiomata were the same as those described by Steyaert $(1967,1975)$ and Ho and Nawawi (1986).

\section{Isolation of Ganoderma Mycelium}

Isolation of mycelium was made from the basidiomata. Small pieces of basidiomata ( $4 \mathrm{~mm} \times 4 \mathrm{~mm} \times 5 \mathrm{~mm}$ ) were cut and surface sterilised with $5 \%$ sodium hypochloride for $3 \mathrm{~min}, 0.1 \% \mathrm{HgCl}_{2}$ for $1 \mathrm{~min}$, and $2 \%$ sodium hypochloride for 2 min, blotted dry and plated on malt agar (MA) with streptomycin sulphate in Petri dishes. Visible mycelia grown from the pieces of basidiomata were subcultured onto fresh MA medium in Petri dishes. 


\section{Somatic Incompatibility Studies}

The Ganoderma isolates studied are listed in Table 1. The isolates were paired in all combinations i.e. from the same oil palm tree or from different trees within the same estate or different estates. The procedures used were similar to those described by Latiffah et al (2002), and the interactions between the isolates were rated as degrees of antagonism according to the ratings by Adaskaveg and Gilbertson (1987) i.e. $0=$ compatible, $1=$ weak, 2 = moderate and $3=$ strong.

Table 1: Ganoderma boninense isolates used in somatic incompatibility study

\begin{tabular}{|c|c|c|}
\hline \multicolumn{3}{|c|}{ Ganoderma Isolate } \\
\hline $\begin{array}{l}\text { Bukit Serampang } \\
\text { (BS) Estate }\end{array}$ & Regent (R) Estate & $\begin{array}{l}\text { Paya Lang (PL) } \\
\text { Estate }\end{array}$ \\
\hline 09BS2 & $11 \mathrm{RG} 1$ & 13PL1 \\
\hline 09BS3 & 11RG2 & 13PL2 \\
\hline 09BS4 & $15 R G 1$ & 13PL4 \\
\hline 22BS1 & 15RG2 & 23PL1 \\
\hline 22BS2 & 15RG3 & 23PL2 \\
\hline 39BS3 & 39RG1 & 32PL2 \\
\hline 39BS4 & 39RG2 & $32 \mathrm{PL} 3$ \\
\hline 39BS5 & 04RG2 & 38PL2 \\
\hline $13 B S 1$ & 04RG3 & 38PL4 \\
\hline 14BS2 & 04RG4 & 14PL4 \\
\hline $16 \mathrm{BS} 1$ & 17RG3 & 07PL2ii \\
\hline 21BS1 & $18 R G 1$ & 39PL1 \\
\hline 37BS2 & 19RG2 & \\
\hline 40BS2 & 37RG2 & \\
\hline \multicolumn{3}{|l|}{ 10BS1D } \\
\hline 14BS3D & & \\
\hline
\end{tabular}

Note: Isolates with the same alphabets and the same numbers in front of the alphabets are from the same oil palm tree. The last number denotes the individual isolates.

\section{RESULTS}

\section{Morphological Characteristics}

The morphological characteristics varied among the basidiomata collected within the same estate as well as between the three estates. The shape of the basidiomata could be sub-ungulate, flabellate, diamidiate or irregular with corrugations and concentric rings. The basidiomata were either sessile or stipitate.

The size of basidiomata from Bukit Serampang Estate ranged from 2.5 to $11.0 \mathrm{~cm}$ in diameter. The majority of the basidiomata were very glossy (index of 4 to 5 ) and the colour ranged from reddish brown (94.8\%) to yellowish brown (5.15\%). The context was 0.25 to $2.5 \mathrm{~cm}$ thick and brownish in colour. The pore tube layer was slightly lighter than the context layer and the thickness ranged from 0.14 to $2.0 \mathrm{~cm}$. The basidiospores were ellipsoidal, $8.5 \times 12.5$ to $6.0 \times 7.5 \mu \mathrm{m}$, yellow to yellowish brown with short, thin echinules. The pores were circular, 100 to $130 \mu \mathrm{m}$ in diameter and the dissepiments were 25 to $120 \mu \mathrm{m}$ thick. The pore surface colour ranged from white to orange.

Basidiomata from Regent Estate were 4.3 to $23.5 \mathrm{~cm}$ in diameter, very glossy (index of 4 to 5 ), and the colour ranged from reddish brown (90.9\%) to yellowish brown $(9.1 \%)$. The thickness of the context layer varied from 0.14 to $2.0 \mathrm{~cm}$ and the pore tube layer from 0.35 to 1.50 $\mathrm{cm}$. The basidiospores were $9.0 \times 12.5$ to $5.5 \times 11.5 \mu \mathrm{m}$, yellowish brown, ellipsoidal with thin short echinules. The pores were circular, $100-200 \mu \mathrm{m}$ in diameter and the dissepiments ranged from 20 to $100 \mu \mathrm{m}$ thick. The colour of the pore surface ranged from white to orange.

The basidiomata from Paya Lang Estate varied from 4.5 to $19.0 \mathrm{~cm}$ in diameter, colour ranged from reddish brown $(86.1 \%)$ to yellowish brown $(13.8 \%)$ with an index of glossiness from 3 to 5 . The context layer ranged from 0.6 to $1.9 \mathrm{~cm}$ and the pore tube layer was 0.5 to $1.5 \mathrm{~cm}$. Like the basidiospores from Bukit Serampang Estate and Regent Estate, the basidiospores were yellow to yellowish brown, ellipsoidal, $8.5 \times 12.0$ to $4.5 \times 6.5 \mu \mathrm{m}$. The pores were also circular about 85 to $300 \mu \mathrm{m}$ in diameter and the dissepiments, 20 to $100 \mu \mathrm{m}$ thick. The pore surface was white.

Although two major colour-types i.e. reddish brown and yellowish brown were observed in the basidiomata from the three estates, variations existed in other morphological characteristics of the basidiomata within each colour-type, and overlapping of morphological characteristics also occurred between the two colourtypes. Based on Steyaert's classification system (1967, 1975), the morphology of the basidomata from the three estates falls within the description of $G$. boninense

\section{Somatic Incompatibility}

Moderate to strong incompatible (antagonistic) reactions were produced in all pairings of isolates except for selfpairs (Tables 2, 3 and 4). The incompatible reactions between two interacting isolates varied from a sparse zone between the isolates, to a clear line of demarcation produced by a raised line of dense hyphae (Figures 1 and 2). Not only isolates of different palms from the same estates or different estates produced incompatible reactions but also isolates from the same palm tree. Incompatible reactions were visible after 7 days and became more distinct after about 10 to 14 days. Compatible reactions in which the mycelia of the two isolates merged and formed a single colony were only observed in self-pairs. 
Mal. J. Microbiol. Vol 1 (2) 2005, pp.46-52

Table 2: Somatic incompatibility of $G$. boninense isolates from Bukit Serampang Estate

\begin{tabular}{|c|c|c|c|c|c|c|c|c|c|c|c|c|c|c|c|c|c|}
\hline & 09BS2 & 09BS3 & 09BS4 & 22BS1 & 22BS2 & 39BS3 & $39 \mathrm{BS} 4$ & 39BS5 & $13 \mathrm{BS} 1$ & 14BS2 & 16BS1 & 21BS1 & 25BS1 & 37BS2 & 40BS2 & 10BS1D & 14BS3D \\
\hline 09BS2 & 0 & & & & & & & & & & & & & & & & \\
\hline 09BS3 & 2 & 0 & & & & & & & & & & & & & & & \\
\hline 09BS4 & 2 & 2 & 0 & & & & & & & & & & & & & & \\
\hline 22BS1 & 2 & 3 & 2 & 0 & & & & & & & & & & & & & \\
\hline 22BS2 & 3 & 3 & 3 & 3 & 0 & & & & & & & & & & & & \\
\hline 39BS3 & 2 & 3 & 3 & 3 & 3 & 0 & & & & & & & & & & & \\
\hline 39BS4 & 3 & 3 & 3 & 2 & 2 & 3 & 0 & & & & & & & & & & \\
\hline 39BS5 & 3 & 3 & 3 & 3 & 2 & 2 & 2 & 0 & & & & & & & & & \\
\hline 13BS1 & 3 & 3 & 3 & 3 & 2 & 3 & 3 & 3 & 0 & & & & & & & & \\
\hline 14BS2 & 2 & 2 & 3 & 2 & 2 & 2 & 3 & 2 & 3 & 0 & & & & & & & \\
\hline $16 B S 1$ & 3 & 3 & 3 & 3 & 3 & 2 & 2 & 2 & 3 & 3 & 0 & & & & & & \\
\hline 21BS1 & 3 & 3 & 3 & 3 & 2 & 3 & 2 & 2 & 2 & 3 & 3 & 0 & & & & & \\
\hline 25BS1 & 3 & 3 & 3 & 3 & 3 & 2 & 2 & 3 & 2 & 3 & 2 & 2 & 0 & & & & \\
\hline 37BS2 & 1 & 3 & 1 & 3 & 3 & 3 & 3 & 3 & 3 & 3 & 3 & 2 & 2 & 0 & & & \\
\hline 40BS2 & 2 & 3 & 3 & 2 & 2 & 3 & 2 & 2 & 3 & 3 & 3 & 2 & 2 & 3 & 0 & & \\
\hline 10BS1D & 2 & 2 & 3 & 3 & 3 & 2 & 3 & 3 & 2 & 2 & 3 & 3 & 3 & 2 & 2 & 0 & \\
\hline 14BS3D & 2 & 3 & 3 & 3 & 3 & 2 & 2 & 3 & 3 & 3 & 2 & 3 & 3 & 3 & 2 & 2 & 0 \\
\hline
\end{tabular}

Note: 1 = weak interaction, 2 = moderate interaction, 3 = strong interaction 
Mal. J. Microbiol. Vol 1 (2) 2005, pp.46-52

Table 3: Somatic incompatibility of $G$. boninense isolates from Paya Lang Estates

\begin{tabular}{|c|c|c|c|c|c|c|c|c|c|c|c|c|}
\hline & 13PL1 & 13PL2 & 13PL4 & 23PL1 & 23PL2 & 32PL2 & 32PL2i & 38PL2 & 38PL4 & 14PL4 & 07PL2ii & 39PL1 \\
\hline 13PL1 & 0 & & & & & & & & & & & \\
\hline 13PL2 & 2 & 0 & & & & & & & & & & \\
\hline 13PL4 & 2 & 2 & 0 & & & & & & & & & \\
\hline 23PL1 & 2 & 2 & 2 & 0 & & & & & & & & \\
\hline 23PL2 & 2 & 2 & 2 & 3 & 0 & & & & & & & \\
\hline 32PL2 & 3 & 3 & 3 & 3 & 3 & 0 & & & & & & \\
\hline $32 \mathrm{PL} 3$ & 3 & 3 & 3 & 3 & 3 & 2 & 0 & & & & & \\
\hline 38PL2 & 3 & 2 & 3 & 2 & 2 & 3 & 3 & 0 & & & & \\
\hline 38PL4 & 3 & 2 & 3 & 2 & 2 & 3 & 3 & 3 & 0 & & & \\
\hline 14PL4 & 3 & 3 & 3 & 3 & 3 & 2 & 2 & 3 & 3 & 0 & & \\
\hline 07PL2ii & 2 & 2 & 2 & 2 & 2 & 3 & 3 & 3 & 2 & 3 & 0 & \\
\hline 39PL1 & 2 & 3 & 2 & 3 & 2 & 3 & 3 & 2 & 2 & 3 & 2 & 0 \\
\hline
\end{tabular}

Note: 1 = weak interaction, 2 = moderate interaction, 3 = strong interaction 
Mal. J. Microbiol. Vol 1 (2) 2005, pp.46-52

Table 4: Somatic incompatibility of $G$. boninense isolates from Regent Estate

\begin{tabular}{|c|c|c|c|c|c|c|c|c|c|c|c|c|c|c|}
\hline & $11 \mathrm{RG} 1$ & 11RG2 & $15 R G 1$ & 15RG2 & 15RG3 & 39RG1 & 39RG2 & 04RG2 & 04RG3 & O4RG4 & 17RG3 & 18RG1 & 19RG2 & 37RG1 \\
\hline 11RG1 & 0 & & & & & & & & & & & & & \\
\hline 11RG2 & 2 & 0 & & & & & & & & & & & & \\
\hline 15RG1 & 3 & 2 & 0 & & & & & & & & & & & \\
\hline 15RG2 & 2 & 2 & 2 & 0 & & & & & & & & & & \\
\hline 15RG3 & 2 & 2 & 2 & 2 & 0 & & & & & & & & & \\
\hline 39RG1 & 3 & 3 & 2 & 3 & 3 & 0 & & & & & & & & \\
\hline 39RG2 & 3 & 3 & 2 & 2 & 3 & 2 & 0 & & & & & & & \\
\hline 04RG2 & 2 & 3 & 2 & 2 & 2 & 2 & 2 & 0 & & & & & & \\
\hline 04RG3 & 3 & 3 & 2 & 2 & 2 & 2 & 3 & 2 & 0 & & & & & \\
\hline O4RG4 & 3 & 3 & 3 & 3 & 3 & 3 & 3 & 3 & 3 & 0 & & & & \\
\hline 17RG3 & 2 & 3 & 3 & 2 & 3 & 2 & 2 & 3 & 2 & 3 & 0 & & & \\
\hline 18RG1 & 3 & 2 & 3 & 3 & 3 & 3 & 3 & 3 & 3 & 3 & 3 & 0 & & \\
\hline 19RG2 & 3 & 3 & 3 & 3 & 3 & 3 & 3 & 3 & 3 & 3 & 3 & 3 & 0 & \\
\hline 37RG1 & 3 & 2 & 2 & 2 & 2 & 2 & 2 & 2 & 2 & 3 & 3 & 3 & 3 & 0 \\
\hline
\end{tabular}

Note: 1 = weak interaction, 2 = moderate interaction, 3 = strong interaction 


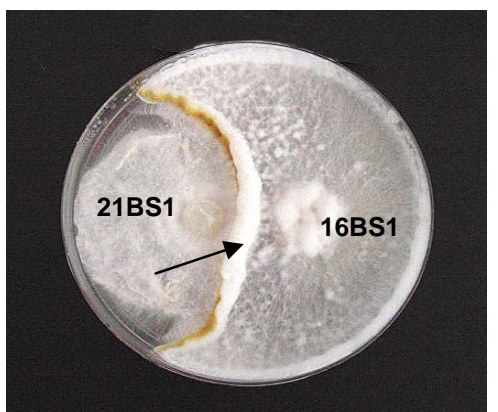

Figure 1: Incompatible reaction between two $G$. boninense isolates, 21BS1 and 16BS1, showing a line of dense and raised hyphae (arrow).

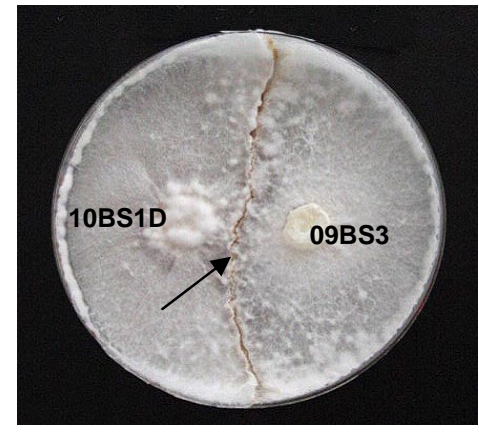

Figure 2: Incompatible reaction between two $G$. boninense isolates, 10BSID and 09BS3, showing a line of demarcation (arrow) between the two isolates

\section{DISCUSSION}

Although variations existed in the morphological characteristics of basidiomata from the three inland estates, the overall morphology of the basidiomata falls within the characteristics of $G$. boninense based on Steyaert's species description $(1967,1975)$. Variations in basidioma characteristics within a species have been reported for several species of Ganoderma and the variations may be caused by different environmental conditions and developmental stages of the basidiomata (Ho and Nawawi, 1985; Adaskaveg and Gilbertson, 1987; Zhao, 1989; Ryverden, 1994).

Ganoderma boninense was first reported by $\mathrm{Ho}$ and Nawawi (1985) to be the most common species associated with the basal stem rot of oil palm. Later, $G$. boninense was also found to be the most common and virulent species in areas with a high disease incidence, such as in the coastal areas (Idris et al., 2000). The results of the present study showed that $G$. boninense is also the species found on infected oil palm in the inland areas.

Somatic incompatibility reactions between all paired isolates (except self-pairs) observed in this study indicate that $G$. boninense isolates within each palm and each estate are genotypically distinct individuals and are not clones of genotypic individuals.

Similar results on somatic incompatibility of Ganoderma isolates within the same estates have been reported by Arifin et al (1996) and Miller et al (1999) which indicated that the Ganoderma populations are highly heterogenous over localized areas.

The presence of different genotypically distinct individuals suggests that the spread of the basal stem rot disease within an estate may not have occurred by mycelial spread from neighbouring infected palms. The numerous distinct individuals could have arisen via basidiospores. Although the role of basidiospores in disease infection is still unclear, they can colonise dead coconut and oil palm stumps and trunks left on the ground or buried in the soil which then can serve as inoculum for the basal stem rot disease of oil palms (Turner, 1981). The occurrence of genetically distinct individuals within an oil palm estate may also have originated from secondary inoculum sources such as infected debris left from the previous crop. A study by Abdullah (2000) suggested that disease infection and spread was from infected residues left in the soil.

In conclusion, although variations occurred in the morphological characteristics of Ganoderma basidiomata from the three inland estates, the Ganoderma falls within the description of $G$. boninense based on Steyaert's classification $(1967,1975)$. Somatic incompatibility shown by the isolates within each estate and within individual palms indicates that they are genotypically distinct individuals.

\section{ACKNOWLEDGEMENT}

We would like to thank IOI Plantation for providing the Ganoderma basidiomata from the three inland estates for this study.

\section{REFERENCES}

Abdullah, F. (2000). Spatial and sequential mapping of the incidence of basal stem rot of oil palm (Elaeis guineensiss) on a former coconut (Cocos nucifera) plantation. In: Ganoderma Diseases of Perennial Crops. J. Flood., P. D. Bridge and P.Holderness. (eds). CABI Publishing, Wallingford,United Kingdom. pp. 183 - 194.

Adaskaveg, J.E. and Gilbertson, R. L. (1987). Vegetative incompatibility between intraspecific dikaryotic pairings of Ganoderma lucidum and $G$. tsugae. Mycologia 79: 603-613.

Arifin, D., Idris, A. S. and Marzuki, A (1996). A26: Spread of Ganoderma boninense and vegetative compatibility studies of a single field palm isolates. Proceedings of the 1996 PORIM International Palm Oil Congress (Agriculture). pp. 317-329.

Benjamin, M. and Chee, K.H. (1995). Basal stem rot of oil palm - a serious problem on inland soils. MAPPS Newsletter 19(1): 3. 
Ho, Y. W. and Nawawi, A. (1985). Ganoderma boninense Pat. from basal stem rot of oil palm (Elaies guineensis) in Peninsular Malaysia. Pertanika 8: 425 $-428$.

Ho, Y. W. and Khairuddin, H. (1995). Pathogenicity and histopathology of Ganoderma boninense on oil palm seedlings. Journal of Bioscience 6: 155 - 164.

Idris, A. S, Arifin, D., Swinburne, T. R. and Watt, T. A. (2000). The identity of Ganoderma species responsible for BSR disease of oil palm in Malaysia Morphological Characteristics. Malaysian Palm Oil Board 102 : 77a.

Latiffah, Z, Ho, Y.W., Tan, S .G., Abdullah, F. and Harikrishna, K. (2002). Morphological and growth characteristics and somatic incompatibility of Ganoderma from infected oil palm and coconut. Malaysian Applied Biology 31(1): 37 - 48.

Khairudin, H. (1990). Basal stem rot of oil palm: Incidence, Etiology and Control. Master science thesis. Universiti Pertanian Malaysia, Serdang, Selangor.

Miller, R. N. G., Holderness, M., Bridge, P. D, Chung, G. F. and Zakaria, M.H. (1999). Genetic diversity of Ganoderma in oil palm plantings. Plant Pathology 48: $595-603$.
Navaratnam, S. J. (1964). Basal stem rot of oil palm on ex-coconut estates. Planter 40: 256 - 259.

Ryverden, L. (1994). Can we trust morphology in Ganoderma? In: Ganoderma, Systematics, Phytopathology and Pharmacology. P.K. Buchanan, R.S., Hseu and J.M. Moncalvo. (eds). Proceedings of Contributed Symposium 5A, B. $5^{\text {th }}$ International Mycological Congress, Vancouver, August $14-21$. pp. $19-24$.

Singh, G. (1991). Ganoderma - the scourge of oil palms in the coastal areas. Planter 67: 421 - 444.

Steyaert, R.L. (1967). Les Ganoderma palmicoles. Bulletin Jardin Botanique Nationale Belgique 37: 465 $-492$.

Steyaert, R. L. (1975). CMI Descriptions of Pathogenic Fungi and Bacteria. No. 444. Commonwealth Mycological Institute, Surrey, England.

Thompson, A. (1931). Stem rot of the oil palm in Malaya. Bulletin Department of Agriculture, Straits Settlements and F.M.S., Science Series 6: 23 pp.

Turner, P. D. (1981). Oil Palm Diseases and Disorders. Oxford, New York: Melbourne Oxford University Press.

Zhao, J.D. (1989). The Ganodermataceae in China. Bibliotheca Mycologica 132. J. Craner, Berlin, Stuttgart. 